\title{
Prospectiva para a indústria química do Brasil: uma visão para o futuro
}

\author{
Adelaide Maria de Souza Antunes* \\ Paola Galera ${ }^{* *}$ \\ Luis Rubinstein ${ }^{* * *}$
}

RESUMO - Motivado pela proclamação de 2011 como sendo o Ano Internacional da Química, o presente artigo introduz uma discussão sobre a prospectiva da indústria química brasileira. Possui como objetivo subsidiar o planejamento estratégico tecnológico do Brasil para os próximos anos. No trabalho são apresentadas as principais tendências para a indústria química mundial e as necessidades do Brasil para o seu desenvolvimento e competitividade global.

Palavras-chave: Indústria química. Indústria petroquímica. Mapa prospectivo. Visão de futuro.

\section{INTRODUÇÃO}

As perspectivas da indústria química estão vinculadas às macro questões globais, e isso inclui as expectativas da economia, o peso sempre crescente das preocupações ambientais, a flutuação nos preços do petróleo e gás, o sucesso nas novas tecnologias de produção de matérias-primas da biomassa e o perfil de consumo da sociedade.

Para se consolidar como uma indústria química competitiva a nível mundial, o Brasil precisa investir na qualificação de recursos humanos, em matérias-primas competitivas, na organização de sua estrutura industrial e em infraestrutura logística.

Como a disponibilidade de matérias-primas é um elemento-chave para o sucesso da indústria química, detalham-se mais especificamente as áreas necessárias para o desenvolvimento da indústria petroquímica, em razão da situação peculiar em que o país se encontra, ou seja, autossuficiente em petróleo. E dentro de pouco tempo também o será em gás natural. Além disso, o Brasil tem uma posição privilegiada como produtor agrícola e, consequentemente, de derivados da biomassa, que vêm rapidamente desenvolvendo alternativas importantes aos produtos petroquímicos, com vantagem de serem fontes renováveis e considerados menos poluentes.

O presente artigo introduz a discussão sobre a prospectiva da indústria química bra-

\footnotetext{
* Doutora em Engenharia Química pela Universidade Federal do Rio de Janeiro. É especialista sênior do Instituto Nacional da Propriedade Industrial e professora permanente do Programa de Pós-Graduação de Tecnologia de Processos Químicos e Bioquímicos da Escola de Química da Universidade Federal do Rio de Janeiro. Endereço eletrônico: aantunes@inpi.gov.br.

** Engenheira Química pela Universidade Federal do Rio de Janeiro. É pesquisadora do Sistema de Informação sobre a Indústria Química (SIQUIM). Endereço eletrônico: paolagalera@gmail.com.

*** Mestre em Engenharia Química pela Universidade Federal do Rio de Janeiro. Endereço eletrônico: luisrubinstein@terra.com.br.
} 
sileira, e tem como objetivo subsidiar o planejamento estratégico tecnológico. Possui como grande motivador a proclamação de 2011 como sendo o Ano Internacional da Química, tornando-se oportuno discernir sobre o futuro da indústria química no Brasil.

\section{INDÚSTRIA QUÍMICA BRASILEIRA ATUAL}

A indústria química brasileira é a oitava maior indústria química do mundo. De acordo com os dados da Associação Brasileira da Indústria Química - Abiquim, seu faturamento líquido, em 2010, foi de US\$130,2 bilhões, representando a participação de 2,6\% no PIB total do país.

Os produtos químicos representam a quarta maior participação no PIB industrial, sendo somente superados pela indústria de produtos derivados do petróleo, alimentos e bebidas e veículos automotivos.

Pela classificação da Abiquim, a estrutura da indústria química brasileira se subdivide em: produtos químicos de uso industrial; produtos farmacêuticos; higiene, perfumaria e cosméticos; adubos e fertilizantes; defensivos agrícolas; produtos de limpeza; tintas, esmaltes e vernizes; e fibras.

Os produtos químicos de uso industrial são os que apresentam o maior faturamento, e incluem os produtos inorgânicos, produtos orgânicos, resinas e elastômeros e produtos e preparados para químicos diversos. Em 2010, este grupo de produtos representou cerca de $50 \%$ do faturamento líquido da indústria química brasileira.

Em termos de balança comercial, os produtos químicos apresentaram, em 2010, um déficit superior a US $\$ 20$ bilhões, cerca de $70 \%$ provenientes de produtos químicos de uso industrial e 25\% provenientes do segmento de adubos e fertilizantes (ABIQUIM, 2011).

Comparando o Brasil às grandes potências mundiais da indústria química, Estados Unidos e China, o país ainda apresenta um grande distanciamento em termos de faturamento. Como pode ser observado na Tabela 1, em 2009, o Brasil obteve por volta de 6,67 vezes menos volumes financeiros em vendas quando comparado aos Estados Unidos. Este fato pode ser compreendido pelas diferenças nos indicadores macroeconômicos entre esses países. Enquanto o PIB dos Estados Unidos, em 2009, foi de US\$ 14,1 trilhões, o PIB brasileiro foi de US\$1,6 trilhão. Ainda assim, o país ocupa a oitava posição da indústria química mundial.

Um dos entraves para o desenvolvimento da indústria química brasileira se deve ao hiato ainda existente entre o avanço científico e tecnológico. A universidade esteve, por muitos anos, distante da tecnologia e de sua aplicação real. Este fato pode ser observado pelos dados atuais de significativas publicações científicas e poucas inovações tecnológicas. 
TABELA 1 - FATURAMENTO DA INDÚSTRIA QUÍMICA MUNDIAL EM 2009 E PIB DOS RESPECTIVOS PAÍSES

\begin{tabular}{|c|c|c|c|c|c|}
\hline$\#$ & País & $\begin{array}{l}\text { Faturamento da } \\
\text { indústria química } \\
\text { (US\$ bilhões) }\end{array}$ & $\begin{array}{c}\text { PIB } \\
\text { (US\$ bilhões) }\end{array}$ & $\begin{array}{l}\text { População } \\
\text { (milhões) }\end{array}$ & $\begin{array}{l}\text { PIB per capita } \\
\text { (em US\$ mil) }\end{array}$ \\
\hline 1 & Estados Unidos & 674 & 14.119 & 307 & 45,9 \\
\hline 2 & China & 635 & 4.991 & 1.335 & 3,7 \\
\hline 3 & Japão & 286 & 5.033 & 128 & 39,5 \\
\hline 4 & Alemanha & 213 & 3.339 & 82 & 40,8 \\
\hline 5 & França & 135 & 2.656 & 63 & 42,4 \\
\hline 6 & Itália & 105 & 2.117 & 60 & 35,3 \\
\hline 7 & Coreia & 104 & 833 & 49 & 17,1 \\
\hline 8 & Brasil & 101 & 1.601 & 191 & 8,4 \\
\hline 9 & Reino Unido & 97 & 2.182 & 62 & 35,3 \\
\hline 10 & Índia & 93 & 1.269 & 1.199 & 1,1 \\
\hline 11 & Holanda & 66 & 797 & 17 & 48,2 \\
\hline 12 & Espanha & 65 & 1.468 & 46 & 32,0 \\
\hline 13 & Rússia & 64 & 1.222 & 142 & 8,6 \\
\hline
\end{tabular}

FONTE: Abiquim e International Monetary Fund, World Economic Outlook Database, 2011.

Levando em consideração as publicações científicas, as previsões são que o Brasil chegue, nos próximos anos, ao ranking dos dez países que mais publicam no mundo. Atualmente, representa $2 \%$ da produção mundial de artigos e ocupa a $13^{\text {a }}$ posição do ranking de publicações, liderado respectivamente pelos Estados Unidos, China, Alemanha, Japão, Inglaterra, França, Canadá, Itália, Espanha, Índia, Austrália e Coreia do Sul (THOMSON REUTERS, 2009).

Entretanto, este desempenho em termos científicos não garante o desenvolvimento tecnológico no país. O Brasil é tradicionalmente comprador de tecnologia química. A dependência tecnológica influenciou negativamente o hábito de patenteamento brasileiro, tanto pelas indústrias quanto pelas universidades. De acordo com dados de 2009 da Organização Mundial da Propriedade Intelectual - OMPI, o Brasil não passa de 0,32\% dos pedidos de patentes internacionais.

Analisando o número de patentes concedidas nos Estados Unidos, as empresas brasileiras obtiveram, em 2009, apenas 146 patentes, enquanto que as coreanas 9.400 e as americanas 93.700. Estes dados evidenciam os baixos gastos com Pesquisa e Desenvolvimento (P\&D) no país. Enquanto o Brasil gasta apenas 1,1\% do PIB com P\&D, os EUA gastam 2,6\% e a Coreia 3,2\% (MENEZES FILHO, 2010). A comparação entre a Coreia e o Brasil se torna importante se considerarmos que há cinquenta anos a Coreia era um país dos mais atrasados, com uma economia baseada em agropecuária rudimentar e altas taxas de analfabetismo (O’NEILL, 2007).

O desafio que se tem à frente é o de desenvolver tecnologia de ponta, voltada não exclusivamente ao mercado interno, mas também para inserir o Brasil no mercado externo. Para tal, a indústria nacional precisa solucionar problemas existentes e que aumentam a sua defasagem em relação aos principais competidores mundiais: tributação excessiva, infraestrutura 
deficiente, custo de capital elevado, nível educacional da mão de obra inadequado - ao lado de fatores mais específicos, como os custos de insumos industriais (nafta, gás natural e energia).

\section{VISÃO DE FUTURO}

Partindo do pressuposto de que a indústria química mundial é em grande parte madura e que muitos dos seus produtos são commodities baseadas em tecnologias bem estabelecidas, o avanço da indústria química nos mercados desenvolvidos deverá ocorrer a partir de possibilidades de inovações em especialidades químicas e novas funcionalidades, obtidas graças às novas tecnologias de processo e às novas metodologias de controle de microestruturas. Destaca-se, portanto, boa perspectiva de avanço científico em áreas como biotecnologia e nanotecnologia.

Como pode ser observado no Gráfico 1, verifica-se, a partir de 1970, a redução do faturamento nos produtos químicos básicos e um incremento em especialidades químicas e ciências da vida, grupos de maior crescimento e rentabilidade, e com maior investimento em P\&D.

GRÁFICO 1 - 50 ANOS DO FATURAMENTO DA INDÚSTRIA QUÍMICA MUNDIAL

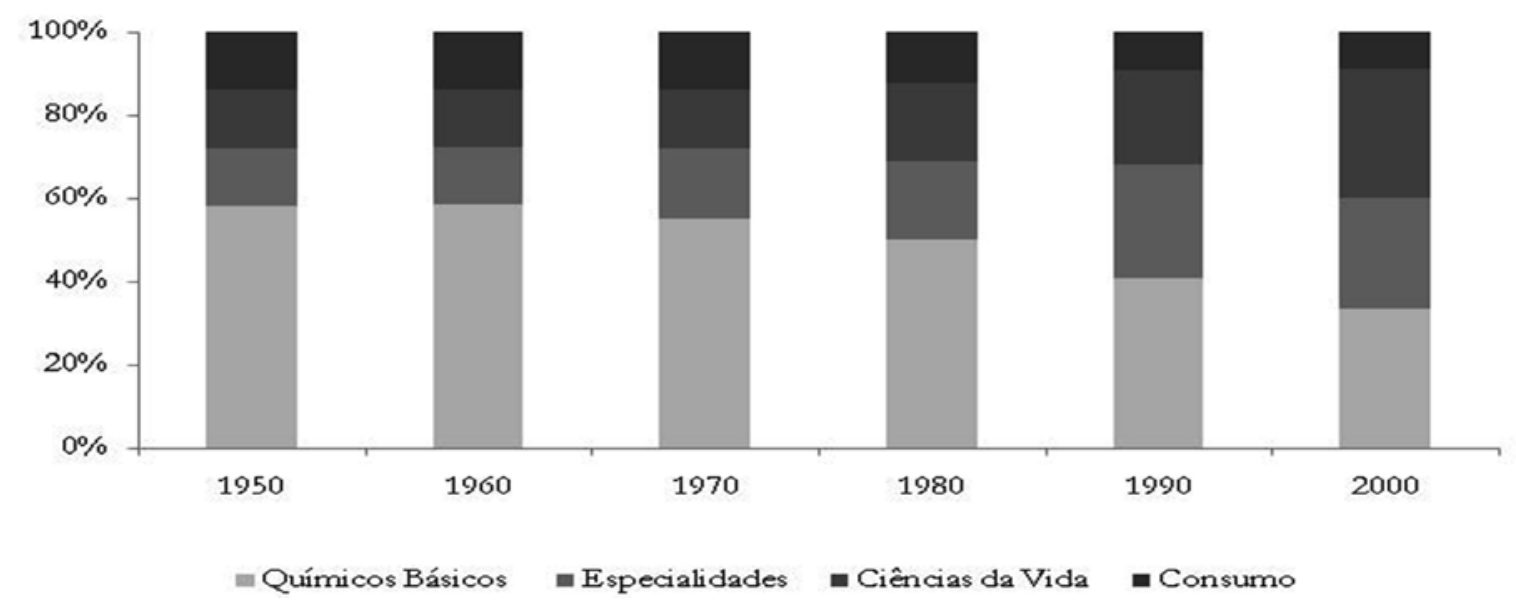

FONTE: ACC (2003), apud TAKAKURA (2005).

Para uma visão de futuro, a associação de documentos prospectivos internacionais em conjunto com a análise macroeconômica brasileira permite a elaboração de panoramas onde podem ser previstos os movimentos futuros da indústria química brasileira. Sempre lembrando que o cenário nunca é uma figura definitiva, porém um ponto de início para o diálogo.

Nos Estados Unidos, o documento intitulado Technology Vision 2020: The U.S. Chemical Industry foi elaborado por mais de 200 técnicos e líderes de negócios pertencentes à indústria química americana. $\mathrm{O}$ documento estuda o futuro da indústria química e as principais forças de mudanças necessárias para promover o desenvolvimento sustentável, estimulando o 
crescimento industrial e equilibrando necessidades econômicas com as restrições financeiras. Os principais desafios para a indústria química apontados por este estudo envolvem o balanço das necessidades entre meio ambiente e as considerações econômicas, e o comprometimento com gastos em $\mathrm{P} \& \mathrm{D}$, através de investimentos compartilhados em tecnologia, por meio de consórcios entre governo, empresas privadas, universidades e centros de pesquisas.

$\mathrm{Na}$ Europa, o documento Horizons2020 identificou megatendências, para as indústrias em geral, que são inevitáveis e que terão forte influência sobre o futuro da economia, tecnologia, política e sociedade. Destacam-se o envelhecimento da população, o aumento da globalização, a redução da taxa de natalidade, o aumento da importância das mulheres na economia e sociedade, o aumento das comunidades virtuais, o aumento da mídia de comunicação e a crescente busca por conhecimento tecnológico.

O Brasil deve estar atento a esses desafios e tendências prospectados pelas indústrias americanas e europeias, para que possa se desenvolver e conseguir uma posição de destaque no cenário internacional.

\section{DESAFIOS E TENDÊNCIAS PARA A INDÚSTRIA QUÍMICA BRASILEIRA}

Os desafios atuais apontados para a indústria de maneira geral, e aplicados à indústria química brasileira, passam por pontos que envolvem principalmente a qualificação de recursos humanos, a organização da estrutura da indústria atual, matérias-primas competitivas e a infraestrutura logística. Cada um destes pontos será discutido a seguir.

\subsection{RECURSOS HUMANOS QUALIFICADOS}

Os procesos químicos industriais são desenvolvidos pelo uso intensivo de conhecimento, ciência, tecnologia e engenharia, necessitando de profissionais altamente qualificados. O desenvolvimento da indústria química depende, portanto, da disponibilidade de mão de obra qualificada. No Brasil, existem deficiências importantes nesse campo, que se associam claramente ao sistema educacional e ao ensino profissional (ABIQUIM, 2010), principalmente no que diz respeito à mudança da escala de bancada para a escala piloto, para transformar pesquisa básica em tecnológica.

O Serviço Nacional de Aprendizagem Industrial - SENAI, um dos mais importantes polos nacionais de geração e difusão de conhecimento aplicado ao desenvolvimento industrial, realizou, em 2005, uma prospecção tecnológica identificando tecnologias emergentes para o setor petroquímico, o setor mais influente da indústria química (ANTUNES; COUTINHO, 2005). Este estudo indicou que as empresas do setor petroquímico buscam um perfil profis- 
sional que englobe determinadas competências pessoais, destacando a consciência ecológica e social, o trabalho em equipe, criatividade, empreendedorismo, visão global, foco no cliente, aprendizagem contínua e pró-atividade. Investindo na formação de recursos humanos qualificados é possível ampliar a base científica e tecnológica do país.

\subsection{ESTRUTURA INDUSTRIAL}

No mercado globalizado, principalmente na produção petroquímica, é necessário diminuir a vulnerabilidade com a diversificação da produção e com o aumento de escala. No Brasil, somente em 2002, com a criação da Braskem, o segmento petroquímico deixou de ser um aglomerado de empresas de pequeno porte, monoprodutoras, não integradas, de difícil integração no processo de globalização.

A Braskem foi criada por meio da integração do capital da Companhia Petroquímica do Nordeste S. A. - Copene (central de matérias-primas do Polo Petroquímico de Camaçari), OPP Química S. A., Trikem, Propet, Nitrocarbono e Poliladen. Em novembro de 2007, em nova composição acionária com a Petrobras, integrou os ativos da Copesul, Ipiranga Química, Ipiranga Petroquímica, Petroquímica Paulínia e Petroquímica Triunfo. Mais recentemente, em 2010, incorporou a Quattor, formada a partir da consolidação dos ativos das empresas Rio Polímeros, Suzano Petroquímica, da Petroquímica União e Unipar. Atualmente, a empresa já apresenta movimentos internacionais, com plantas em funcionamento nos Estados Unidos, e projetos em andamento e estudos no Peru, Venezuela e México.

A partir dessa grande reestruturação na petroquímica é que o Brasil pode almejar se tornar um importante player mundial em resinas de polietileno e polipropileno. É importante que o Brasil desenvolva outras empresas de grande porte, e parte deste desafio poderá ser superado com a implantação do Complexo Petroquímico do Rio de Janeiro - o Comperj, empreendimento da Petrobras que terá participação da Braskem, previsto para iniciar suas operações em 2014. O Comperj deverá aumentar de forma expressiva a oferta de petroquímicos básicos no país, bem como a de resinas.

\subsection{MATÉRIAS-PRIMAS}

As principais fontes de matérias-primas para a indústria química como um todo, e principalmente para a petroquímica, o ponto de partida da indústria química, são a nafta e o gás natural. Para o Brasil aumentar a competitividade em produtos petroquímicos, torna-se necessário o desenvolvimento de novas tecnologias no sentido de se conseguir obter a nafta a partir das reservas existentes de óleos pesados e ultrapesados e, futuramente, aumentar a oferta de gás 
natural, devido à descoberta da camada do pré-sal.

No primeiro caso, está prevista a geração de produtos petroquímicos básicos, as olefinas geradas a partir da nafta e/ou do gás natural e os aromáticos da nafta. Ao entrar em operação, o Comperj deverá levar a uma substancial expansão da oferta destes produtos a partir do petróleo nacional pesado e também do gás natural.

O eteno e o propeno ocupam o primeiro lugar em importância como produtos básicos, ponto de partida da indústria petroquímica, pois são precursores para os principais polímeros e intermediários para todos os setores químicos. Além do processo de craqueamento da nafta e a separação do etano e propano do gás natural, tem-se, atualmente, a tecnologia de conversão do gás natural em olefinas, conhecida como GTO (Gas to Olefins). Nela, primeiramente é feita a conversão do gás natural em metanol e, posteriormente, a conversão do metanol em olefinas, principalmente eteno, propeno e buteno. O processo específico a partir do metanol é conhecido como MTO (Methanol to Olefins), e inclui o processo MTP (Methanol to Propylene).

Apesar de o polietileno ser o polímero de maior produção, o polipropileno vem apresentando as maiores taxas de crescimento produtivo, sendo obtido pela polimerização do propeno. Para a complementação da produção do propeno existem rotas alternativas, como o processo de metátese do eteno com o 2-buteno (este obtido na dimerização do eteno) ou pelo processo MTO, já mencionado anteriormente.

Em relação às matérias-primas renováveis, a Abiquim desenvolveu, em 2010, o Pacto Nacional da Indústria Química, onde um dos seus objetivos é tornar o país líder em Química Verde. Além disso, o Pacto pretende posicionar a indústria química brasileira entre as cinco maiores do mundo, e tornar o país superavitário em produtos químicos. Para isso, prevê um investimento de US\$ 167 bilhões pelas empresas do setor até 2020, para que as indústrias químicas e petroquímicas consigam atender à demanda nos próximos dez anos e zerar o déficit da balança comercial.

Um dos primeiros frutos deste movimento é a iniciativa da Braskem com uma unidade de polietileno verde, obtido a partir do etanol da cana-de-açúcar. A planta foi inaugurada em 2010, e a empresa já prevê para 2013 uma unidade de polipropileno verde. O principal desafio da utilização do etanol como matéria-prima é a redução dos custos de obtenção para valores competitivos com o do petróleo ou da nafta.

No Brasil, particularmente, o etanol é o grande produto da química verde, principalmente pelo seu uso como biocombustível. Portanto, continua sendo objeto de contínuos esforços de vários grupos de pesquisa nas universidades, para o desenvolvimento de tecnologias de segunda geração, a partir de resíduos agroflorestais, principalmente a biomassa lignocelu- 
lósica, para aumentar a produtividade do etanol, uma vez que a maior participação de fontes renováveis garante melhor condição ambiental, além da diminuição do custo pelo aumento da produtividade.

A produção de matérias-primas a partir da biomassa a preços competitivos com o do petróleo e, também, um agronegócio com liderança internacional, são os objetivos da constituição das chamadas biorrefinarias. Novas rotas bioquímicas e biocatalisadores têm como atrativo a obtenção de produtos através de condições mais brandas de produção, implicando menores investimentos. Neste sentido, a produção de enzimas passa a ser alvo para uso como biocatalisadores de alta seletividade. Deve-se também explorar a produção de diácidos orgânicos por rota sucroquímica, como, por exemplo, o ácido succínico, ponto de partida para uma série de intermediários químicos para as biorrefinarias.

Aliados à produção do polietileno verde por rota alcoolquímica, outros biopolímeros, classificados estruturalmente como polissacarídeos, poliésteres ou poliamidas, são considerados promissores: o polilactato (PLA), poli-hidroxialcanoato (PHA), polímeros de amido (PA) e xantana (Xan). Vários desses bioplásticos alcançaram o mercado a partir da década passada, mas ainda esbarram em custos superiores aos polímeros sintéticos convencionais. Com isso, o foco da pesquisa e desenvolvimento está na melhoria do rendimento e na redução dos custos de processamento, empregando novas técnicas da moderna biotecnologia (BASTOS, 2007).

\subsection{INFRAESTRUTURA LOGÍSTICA}

A indústria química é uma atividade econômica que processa grandes volumes e que requer uma integração entre diferentes etapas e processos, conforme já mencionado. Pela sua conformação histórica, os polos produtivos se situam a grandes distâncias dos principais mercados. Portanto, para o seu funcionamento e a sua competitividade, os polos requerem um elevado grau de integração logística e condições eficientes de transporte, e o Brasil, atualmente, apresenta deficiências importantes e custos elevados em relação a este aspecto (ABIQUIM, 2010).

O Programa de Aceleração do Crescimento (PAC), lançado em 2007, foi uma ação do Governo Federal brasileiro para incentivar o investimento privado e público na recuperação e na construção de infraestrutura, para alavancar o crescimento do país. Foram realizados projetos prioritários em rodovias, hidrovias, ferrovias, portos, aeroportos, saneamento e recursos hídricos.

Em 2010, foi iniciada uma segunda fase do programa, o PAC 2, com novas propostas para o país continuar crescendo. No que diz respeito à indústria química, na área de refino e 
petroquímica, o PAC 2 prevê investimentos da ordem de R \$130,2 bilhões para ampliação e modernização de unidades existentes, com objetivo de atender à crescente demanda do mercado doméstico, transformar o país em exportador de derivados e petroquímicos e melhorar a qualidade dos combustíveis e derivados, atendendo aos padrões internacionais e ambientais (BRASIL, 2011).

\section{MAPA PROSPECTIVO PARA A INDÚSTRIA QUÍMICA BRASILEIRA}

Com base nos desafios e tendências apresentados, é possível elaborar um mapa prospectivo para a indústria química, explicitando as principais fontes de matérias-primas previstas para os próximos anos, os principais motores para o desenvolvimento da indústria química brasileira, e os principais produtos como visão de futuro. Este mapa é apresentado na Figura 1.

FIGURA 1 - MAPA PROSPECTIVO PARA A INDÚSTRIA QUÍMICA BRASILEIRA

Visão de Futuro para a Indústria Química

\begin{tabular}{|c|c|}
\hline $\begin{array}{l}\text { Fontes de } \\
\text { Matéria-Prima }\end{array}$ & Petróleo Pesado, Gás Natural, Matérias-Primas Renováveis \\
\hline Motores 1 & $\begin{array}{l}\text { Articulação entre os atores: governo, empresários, universidades e centros } \\
\text { de P\&D }\end{array}$ \\
\hline Motores 2 & $\begin{array}{l}\text { Meio Ambiente: redução de gases poluentes, redução gradativa de } \\
\text { combustíveis fósseis }\end{array}$ \\
\hline Motores 3 & Tecnologias: Biotecnologia e Nanotecnologia \\
\hline Produtos & $\begin{array}{l}\text { Olefinas (eteno, propeno), Polímeros, Etanol, Sucroquímica (ácido } \\
\text { succínico), Biopolímeros, Enzimas }\end{array}$ \\
\hline
\end{tabular}

\section{CONSIDERAÇÕES FINAIS}

Como desafios promissores para a indústria química têm-se como resposta a utilização do petróleo pesado como matéria-prima, a transformação do gás natural em produtos petroquímicos básicos e a utilização de matérias-primas renováveis.

Essas áreas são bastante promissoras e o Brasil possui boas condições para que inves- 
timentos nacionais e estrangeiros venham a se estabelecer e desenvolver uma indústria competitiva, inserida no mercado internacional.

Para obter um crescimento sustentável, a indústria brasileira requer a manutenção da estabilidade econômica, redução da tributação, projetos de infraestrutura, acesso ao crédito, avanços na área educacional, aumento na aquisição do conhecimento e maior integração entre governo, empresas e universidades.

A concretização da perspectiva atual de crescimento sustentado da economia brasileira exigirá investimentos em projetos petroquímicos para atender à demanda e evitar déficits crescentes na balança comercial do setor. No entanto, não se pode negligenciar o uso das tecnologias portadoras de futuro, como é o caso da biotecnologia e da nanotecnologia. No Brasil, estas se encontram em fase de pesquisa nas universidades e centros de pesquisa, necessitando que o governo promova consórcios com empresas para o desenvolvimento de produtos com maior valor agregado.

Com relação às matérias-primas renováveis, as condições climáticas e as grandes áreas agriculturáveis colocam o Brasil em condições excepcionais de liderar essa rota tecnológica, porém o país deve evoluir para deixar de ser apenas um produtor em potencial de etanol combustível para se tornar efetivamente um gerador de soluções na área da alcoolquímica, como, por exemplo, através do polietileno verde.

As biorrefinarias surgem como uma solução viável ao país e não podem ficar somente na produção de biocombustíveis; precisam atuar também na produção de produtos químicos, tanto sucroquímicos quanto oleoquímicos, na produção de intermediários para a síntese de polímeros, na produção de diácidos, alcoóis, ésteres e outros produtos.

\section{REFERÊNCIAS}

ABIQUIM - Associação Brasileira da Indústria Química. Pacto nacional da indústria química. São Paulo, 2010.

ABIQUIM - Associação Brasileira da Indústria Química. Disponível em: <http://www.abiquim.org.br/>. Acesso em: 6/2011.

AMERICAN CHEMICAL SOCIETY, AMERICAN INSTITUTE OF CHEMICAL ENGINEERS, AMERICAN CHEMISTRY COUNCIL, COUNCIL FOR CHEMICAL RESEARCH, SYNTHETIC ORGANIC CHEMICAL MANUFACTURERS ASSOCIATION. Technology vision 2020 - the U. S. chemical industry. 1996.

ANTUNES, A. M. S., COUTINHO P. A. Tecnologias prospectadas. Em tempo - setor petroquímico (SENAI), v. 12, p. 4-6, 2005.

BASTOS, V. D. Biopolímeros e polímeros de matérias-primas renováveis alternativos aos petroquímicos. Revista do BNDES, Rio de Janeiro, v. 14, n. 28, p. 201-234, dez. 2007. Disponível 
em: <http://www.bndes.gov.br/SiteBNDES/export/sites/default/bndes_pt/Galerias/Arquivos/conhecimento/revista/rev2807.pdf>. Acesso em: 6/2011.

INTERNATIONAL MONETARY FUND, World economic outlook database. Disponível em: <http://www.imf.org/external/ns/cs.aspx?id=28>. Acesso em: 5/2011.

MENEZES FILHO, N. A. Como aumentar as inovações? Valor Econômico, São Paulo, n. 24 set. 2010. Disponível em: <http://valoronline.com.br/impresso/opiniao/98/313612/comoaumentar-as-inovacoes>. Acesso em: 3/2011.

O’NEILL, J. BRICs and beyonds. Goldman Sachs Global Economic Research, New York, 2007.

BRASIL. Programa de aceleração do crescimento. Disponível em: < http://www.brasil.gov.br/ pac>. Acesso em: 6/2011.

SCHARIOTH, J.; HUBER, M.; SCHULZ, K.; PALLAS, M. Horizons2020: a thought-provoking look at the future. TNS Infratest Wirtschaftsforschung, Munich, n. 18, out. 2004.

TAKAKURA, P. Necessidade da indústria química x formação profissional. In: FÓRUM SOBRE ENSINO DE ENGENHARIA DA ÁREA QUÍMICA, São Paulo, 2005.

THOMSON REUTERS. Journal Citation Report, 2009. 
